\title{
EBSD characterization of pure and K-doped tungsten fibers annealed at different temperatures
}

\author{
L Tanure $^{\mathrm{a}^{*}}$, D Terentyev ${ }^{\mathrm{b}}$, V Nikolićc ${ }^{\mathrm{c}}, \mathrm{J}$ Riesch $^{\mathrm{d}}$ and K Verbeken ${ }^{\mathrm{a}^{*}}$
}

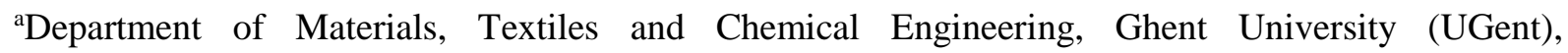
Technologiepark 46, B-9052 Ghent, Belgium

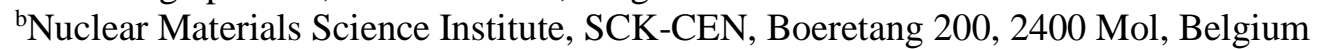

${ }^{\mathrm{c}}$ Erich Schmid Institute of Materials Science, Austrian Academy of Sciences, 8700, Leoben, Austria

${ }^{\mathrm{d} M a x-P l a n c k-I n s t i t u t ~ f u ̈ r ~ P l a s m a p h y s i k, ~} 85748$ Garching, Germany

E-Mail: leandro.tanure@ugent.be and kim.verbeken@ugent.be

\begin{abstract}
Electron Backscatter Diffraction was used to investigate the grain boundary character and triple junction distributions as well as the microtexture on drawn pure and potassium doped (60-75 ppm) tungsten wires. With an approximate diameter of $150 \mu \mathrm{m}$, pure $\mathrm{W}$ wires were annealed at 1300, 1600 and $1900^{\circ} \mathrm{C}$, whereas $\mathrm{K}$-doped material was annealed at 1300,1600 and $2100^{\circ} \mathrm{C}$. The annealing was performed under hydrogen atmosphere for 30 minutes. Both longitudinal and transversal sections were analyzed to assess anisotropic features. Up to $1600^{\circ} \mathrm{C}$, all conditions presented a strong $\langle 110\rangle$ fiber texture parallel to the drawing axis. With increasing annealing temperature, the pure $\mathrm{W}$ material developed a more heterogeneous fiber texture while for the K-doped material, it remained homogeneous. Orientation correlation function (OCF) analysis suggested sub-grain coarsening as the recrystallization mechanism while grain boundary density and grain boundary character distribution exhibited anisotropic behavior, as well as the triple junction distribution network. On the other hand, the coincidence site lattices (CSL) distribution did not present any anisotropy and followed the empirical law of the inverse cubic root of $\Sigma$-value. For all conditions, the most abundant CSL boundaries were $\Sigma 3$, $\Sigma 9, \Sigma 11, \Sigma 17 \mathrm{~b}, \Sigma 19 \mathrm{a}, \Sigma 27 \mathrm{a}$ and $\Sigma 33 \mathrm{a}$. Based on the statistics of the triple junction types and their resistance to intergranular cracking, it was revealed that increasing the annealing temperature might play a role in crack deflection since the resistance to intergranular crack growth is increased in the transversal section and reduced in the longitudinal section. This anisotropic behavior is preserved up to a higher annealing temperature in the K-doped material.
\end{abstract}

Keywords: ITER, EBSD, texture, tungsten fiber, potassium doped, grain boundary, triple junction, annealing

\section{Introduction}

Global warming is a major concern for the present and future generations since the link between anthropogenic greenhouse gas emissions and climate change has been established[1,2]. Considering a sustainable future scenario, alternatives to fossil fuels must increase their share in the world's energy matrix in order to mitigate climate changes, risks and damages[3]. Among the alternatives, nuclear power plays an important role since it does not depend on seasonal factors such as wind and solar power. Although the "traditional" fission-based technology is still in expansion in United States and China, nuclear fusion reactors have the advantage of generating more energy per $\mathrm{kg}$ of fuel and there is no highly radioactive waste. So far, using the currently available devices, fusion reactions do not generate net energy, i.e. they produce less energy than the required amount for sustaining the reaction, but the knowledge on this technology will be largely expanded with the International Thermonuclear Experimental Reactor (ITER) that is under construction in southern France with the first plasma discharge planned by 2025[4]. Besides the main goal of producing net energy on a commercial scale, some studies proposed and showed the feasibility of the transmutation of higher long-term radiotoxicity into shorter lived nuclides using fusion reactors helping to manage the nuclear spent fuel[5-7]. The main challenge for materials scientists with respect to this technology is the plasma confinement. In a TOKAMAK device[4] (acronym from the Russian language for "toroidal chamber with magnetic coils") such as ITER the plasma needs to achieve a temperature about 100 - 200 millions degree Celsius in 
order to overcome the Coulomb repulsion force between particles with the same electric charge and fuse them into a new element releasing energy. The primary confinement mechanism relies on strong magnetic fields that acts on the charged particles and shape the plasma. Nevertheless, the reaction must take place in a vessel and kept insulated from the external environment. The materials that will face the plasma are subjected to extreme conditions and have to meet very specific requirements in order to be used under fusion relevant loading conditions such as elevated operational temperature, high particle flux and cyclic loading conditions [8-12]. The success of this technology on providing large amounts of electricity as a carbon-free and environmentally friendly source of energy relies on the development of plasma-facing components and a better understanding on plasma-wall interactions.

Tungsten-based materials have been extensively investigated as a plasma facing material in the last few decades due to their unique combination of properties e.g. high melting point, high thermal conductivity, high temperature strength and low tritium retention. They became the best candidates to be used as plasma-facing components in future nuclear fusion reactors (ITER) and the demonstration power plant (DEMO)[8,9,13-16]. Although tungsten is currently the suitable candidate, some issues still require further investigation and improvement of the material[17,18].

As other body-centered cubic materials, tungsten exhibits the so called ductile-to-brittle transition temperature caused by the inability of dislocations to perform cross slip causing its intrinsic brittleness below this transition temperature[19]. A possible strategy to mitigate this shortcoming is to reinforce tungsten with tungsten fibers (W-fibers), made of potassium doped tungsten wires. The fiberreinforcement promotes a behavior called extrinsic toughening and relies on controlled energy dissipation mechanisms at the fiber/matrix interfaces[20,21] and it can also promote mechanisms like crack bridging that dissipate energy and relax local stress peaks as reported by Riesch et al.[22] .

Another issue that affects the performance of tungsten is a potential risk of embrittlement caused by a change of microstructure (recrystallization and grain growth) due to overheating during operation. Theoretical consideration on the interaction between dislocations and second phase particles has shown that at high temperatures, elastically soft particles such as gaseous bubbles are a better and more effective alternative to hard particles at suppressing dislocations and grain boundary motion[23]. In incandescent light bulbs where tungsten filaments are subjected to high temperatures, nano-sized potassium bubbles are responsible for strengthening and for the improved creep resistance of tungsten wires[23]. Potassium is introduced via KSiAl-doping before sintering of the ingots. During sintering the KSiAl particles, the silicon and aluminum are removed while the insoluble potassium remains entrapped. Afterwards, when processed by swaging and wire drawing, potassium pores are elongated in the drawing direction into narrow ellipsoids that, upon annealing, breaks up into a single row of spherical bubbles[23-25].

Potassium doping has already proved its efficiency on suppressing secondary recrystallization and controlling grain growth up to $1900^{\circ} \mathrm{C}$ in tungsten thin wires [26-28]. Although these materials have been characterized in terms of microstructure, texture and mechanical behavior [26-34], a dedicated study on the role of both triple junction and grain boundary character distributions is still missing. The main goal of this paper is to assess potential anisotropy in the material and to compare the evolution of both distributions in pure and $\mathrm{K}$-doped $\mathrm{W}$ fibers annealed at different temperatures. The findings could help to improve the performance of the fibers under cyclic tensile load[35]. For a better understanding of the link between microstructure and mechanical behavior, the reader is referred to the literature[2628,31].

\section{Materials and experimental procedures}

Drawn pure (99.9\%) and potassium doped (60-75 ppm) W wires, similar to the ones used in [26,27] were provided by OSRAM GmbH, Schwabmünchen, with a diameter of approximately $150 \mu \mathrm{m}$ [21]. Pure W wires were annealed at 1300,1600 and $1900^{\circ} \mathrm{C}$, whereas $\mathrm{K}$-doped material was annealed at 1300,1600 and $2100^{\circ} \mathrm{C}$. The annealing was performed on $100 \mathrm{~mm}$ long pieces in a tube furnace under 
hydrogen atmosphere for 30 minutes. During this process the samples were placed on a carbon free shovel.

Electron Backscatter Diffraction (EBSD) measurements were performed on both longitudinal and transversal sections of the wires. Pieces of 3-5 mm were embedded in conductive resin and prepared following the standard metallographic procedures of grinding and polishing. The EBSD analysis was performed using a Field Emission Gun Quanta-450 FEI Scanning Electron Microscope with $20 \mathrm{kV}$ acceleration voltage. On the longitudinal sections, the scanned areas varied from $50 \times 100 \mu \mathrm{m}^{2}$ to $150 \mathrm{x}$ $900 \mu \mathrm{m}^{2}$. The specific size of the area was chosen based on the material condition as we aimed to collect a statistically comparable amount of grain boundary and triple junction data for each material. In the transversal sections, the areas were kept at $60 \times 60 \mu \mathrm{m}^{2}$. The step-sizes ranged from 50 to $400 \mathrm{~nm}$ depending on the grain size and the scanned area and are specified in Table 1. Variations in the stepsize were performed in order to find a balance between statistically reliable results, convenient computational time and a limit of 4 million pixels per file to avoid software-related issues during the post-processing step. As the grains become larger with increasing annealing temperature it is necessary to scan larger areas to obtain data from more grains thus larger step-sizes were used (this is more recurrent for the longitudinal section). Post-processing analyses were performed with $\mathrm{OIM}^{\circledR}$ Analysis software. The Neighbor Confidence Index (CI) Correlation (where pixels with low CI are reassigned to match both the crystallographic information and the CI of its first neighbor with the maximum CI) and the Grain CI Standardization (where CIs of all pixels that belong to a grain are replaced by the maximum $\mathrm{CI}$ found among them) data cleanups were applied. Afterwards, pixels with a confidence index below 0.1 were removed from the data set.

Table 1: Step-sizes used for each EBSD analysis.

\begin{tabular}{|l|l|l|l|l|}
\hline \multicolumn{5}{|c|}{ Longitudinal } \\
\hline Pure W & As-received & $1300^{\circ} \mathrm{C}$ & $1600^{\circ} \mathrm{C}$ & $1900^{\circ} \mathrm{C}$ \\
\hline Step-size (nm) & 50 & 200 & 200 & 400 \\
\hline K-doped & As-received & $1300^{\circ} \mathrm{C}$ & $1600^{\circ} \mathrm{C}$ & $2100^{\circ} \mathrm{C}$ \\
\hline Step-size (nm) & 50 & 50 & 100 & 100 \\
\hline \multicolumn{5}{|c|}{ Transversal } \\
\hline Pure W & As-received & $1300^{\circ} \mathrm{C}$ & $1600^{\circ} \mathrm{C}$ & $1900^{\circ} \mathrm{C}$ \\
\hline Step-size (nm) & 50 & 50 & 100 & 100 \\
\hline K-doped & As-received & $1300^{\circ} \mathrm{C}$ & $1600^{\circ} \mathrm{C}$ & $2100^{\circ} \mathrm{C}$ \\
\hline Step-size & 50 & 50 & 50 & 50 \\
\hline
\end{tabular}

Analyses related to grain boundary and triple junctions were collected from three different areas of the same scan i.e. the original area of each scan was divided in three regions of approximately the same area in order to obtain average values and their respective standard deviations. Some analysis of grain boundary character and triple junction distributions were not performed on transversal section of pure W samples annealed at $1900^{\circ} \mathrm{C}$ due to the small amount of grains and triple junctions and the corresponding statistical problems that accompany such analysis (i.e. very large standard deviations on the obtained results).

\section{Results and discussion}

\subsection{Microstructure evolution}

Figure 1 shows Inverse Pole Figure (IPF) overlapped with grain boundary (GB) maps of both pure W and K-doped fibers in the longitudinal section for all analyzed conditions. Figure 2 shows the IPF maps overlapped with GB maps of the same samples but in the transversal section. All the maps from both 
130 Figures 1 and 2 are $30 \times 30 \mu \mathrm{m}^{2}$ to allow better comparison of the microstructural characteristics and 131 the effect of potassium doping among the different conditions.

a) Pure W

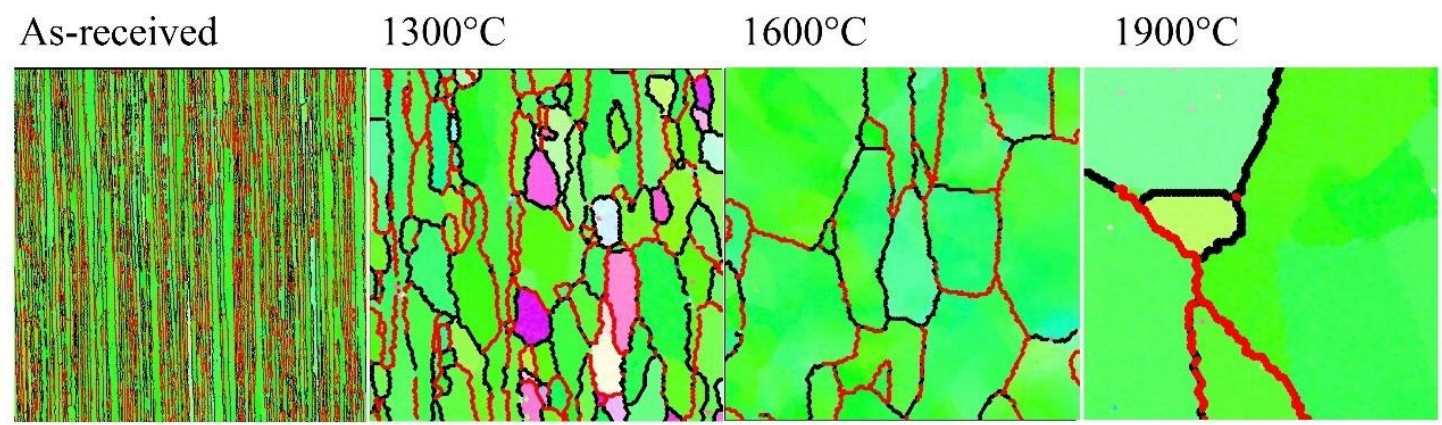

b) K-doped

As-received

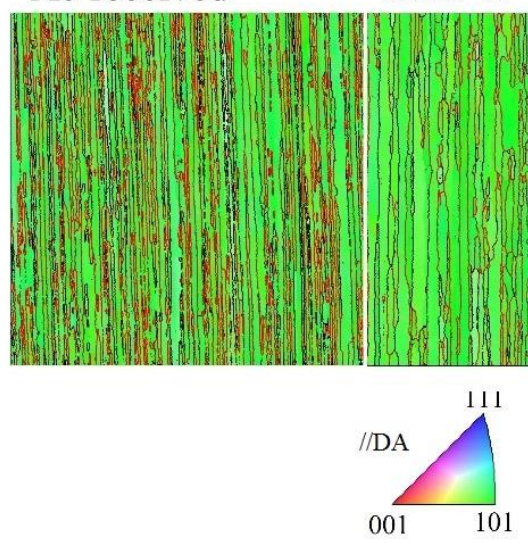

$1600^{\circ} \mathrm{C}$

$2100^{\circ} \mathrm{C}$

Figure 1: Inverse Pole Figure (IPF) overlapped with grain boundary (GB) maps of (a) pure W and (b) K-doped materials in the longitudinal section of all annealed conditions. "Random boundaries" stands for misorientation angles $>5^{\circ}$ while "special boundaries" are coincidence site lattices (CSL). Drawing axis: vertical. Color code with respect to the drawing axis. 
a) Pure W

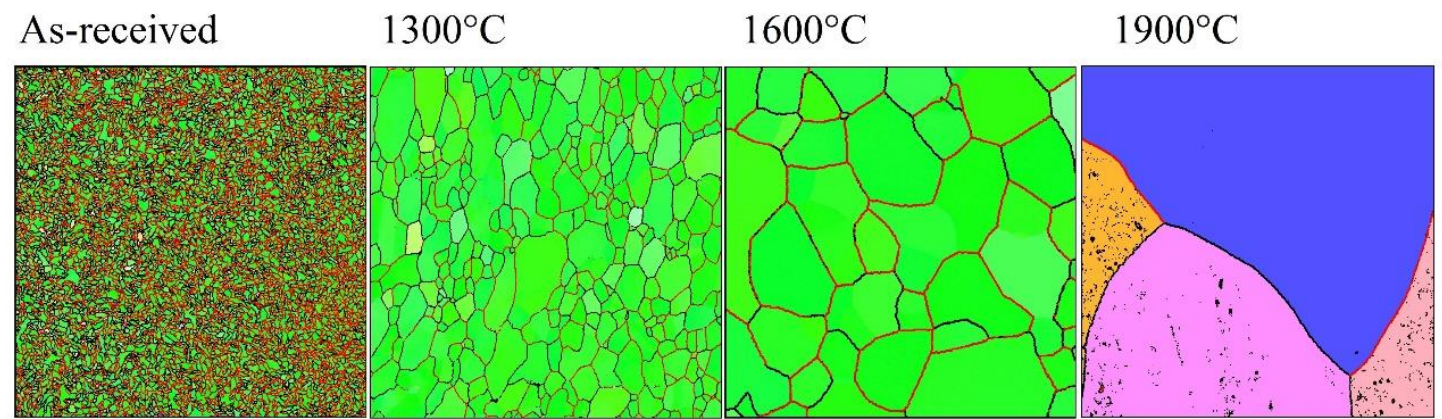

b) K-doped
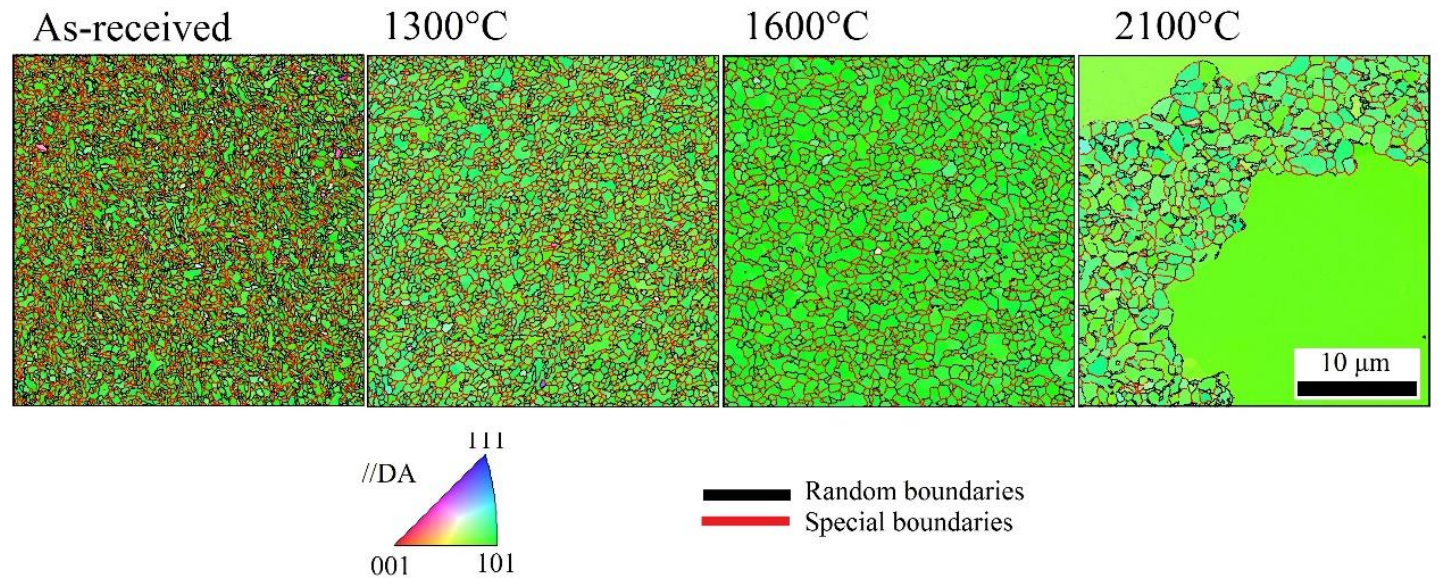

Figure 2: Inverse Pole Figure (IPF) overlapped with grain boundary (GB) maps of (a) pure W and (b) K-doped materials in the transversal section of all annealed conditions. "Random boundaries" stands for misorientation angles $>5^{\circ}$ while "special boundaries" are coincidence site lattices (CSL). Drawing axis: perpendicular to the paper. Color code with respect to the drawing axis.

As can be seen in Figure 1, the "as-received" condition of both materials exhibits elongated grains oriented along the drawing axis (vertical direction) and there are no clear differences in the average length and width, measured by the linear intercept method, that are about 6-9 $\mu \mathrm{m}$ and 0.3-0.6 $\mu \mathrm{m}$, respectively. As previously reported[26], with increasing annealing temperature, the grains tend to become longer and thicker. At $1600^{\circ} \mathrm{C}$, these values change to $10-12$ and 2-4 $\mu \mathrm{m}$ for the pure $\mathrm{W}$ and to 7-9 and 0.8-0.9 $\mu \mathrm{m}$ for the $\mathrm{K}$-doped material. At $1900^{\circ} \mathrm{C}$, the pure $\mathrm{W}$ exhibits large grains in a heterogeneous distribution with average grain size that ranges from 10 to $60 \mu \mathrm{m}$. In the annealed condition of $2100^{\circ} \mathrm{C}$, excessive grain growth takes place in the doped material with a region of small grains confined between two larger grains. These small grains still preserve their elongated shape with average length and width of 8 and $1 \mu \mathrm{m}$, respectively.

Figure 2 also confirms the suppressing effect of K-doping on grain growth in the drawn tungsten wire. The pure material exhibits average grain sizes of $0.36,1.73$ and $4.62 \mu \mathrm{m}$ in the as-received and annealed at 1300 and $1600^{\circ} \mathrm{C}$ conditions, respectively. On the other hand, the K-doped material presents grains with an average size of $0.31,0.51$ and $0.74 \mu \mathrm{m}$ for the same conditions. At $1900^{\circ} \mathrm{C}$, the pure $\mathrm{W}$ material does not exhibit enough grains in the transversal section for a meaningful statistical analysis whereas, at $2100^{\circ} \mathrm{C}$, the $\mathrm{K}$-doped material exhibited a bi-modal grain size distribution that is characteristic for abnormal grain growth. Up to $1600 \mathrm{C}^{\circ}$, the predominance of the green color is a clear indication of a large number of $\langle 110\rangle$ directions parallel to the drawing axis for both materials. Figures 3 and 4 display for the longitudinal and transversal sections, respectively, a quantitative evaluation of the texture 

$<110>/ / \mathrm{DA}$ fiber as a function of the Euler angle $\Phi$.
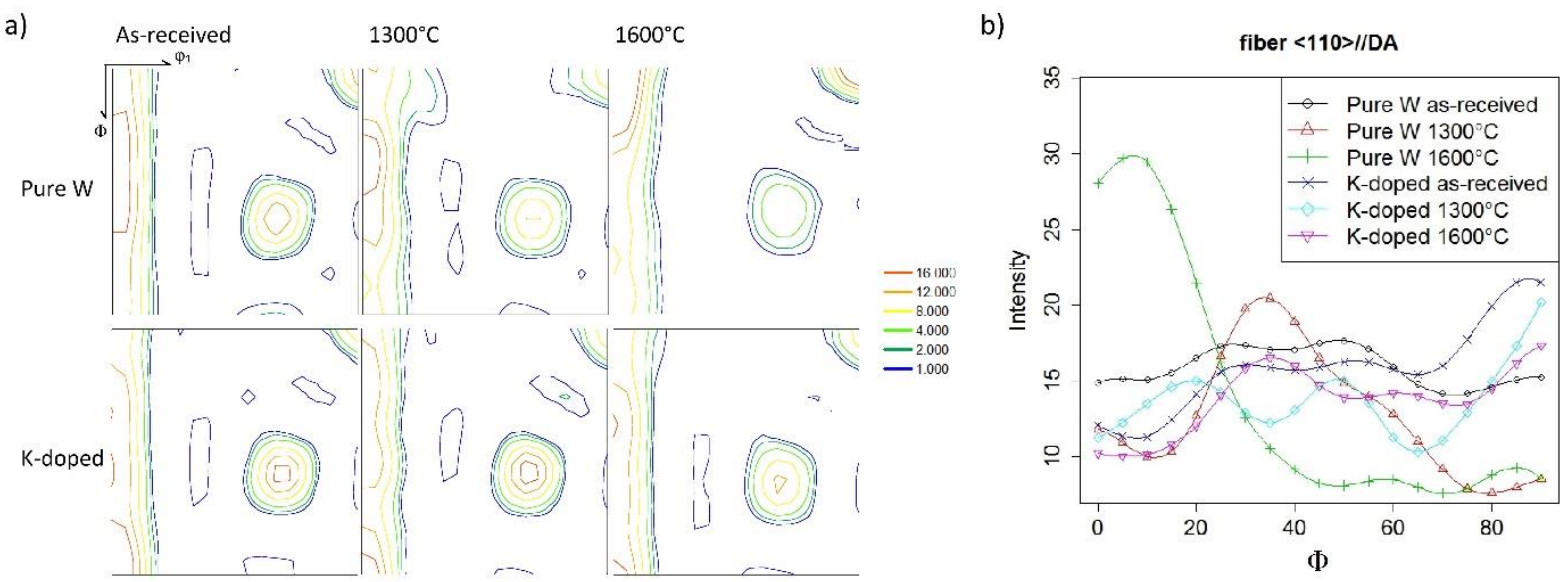

163

164

165

Figure 3: (a) Orientation distribution functions (ODFs) and (b) $\langle 110\rangle$ fiber analysis of the longitudinal section of both materials up to $1600^{\circ} \mathrm{C}$. $\varphi_{1}$ and $\Phi$ range from 0 to $90^{\circ}$. $\varphi_{2}=45^{\circ}$.

a)

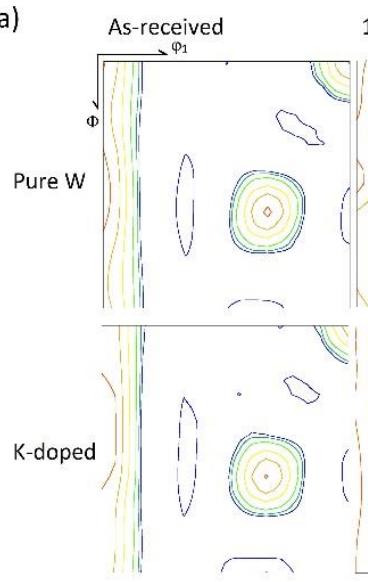
$1300^{\circ} \mathrm{C}$

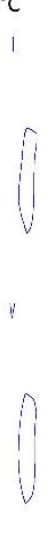

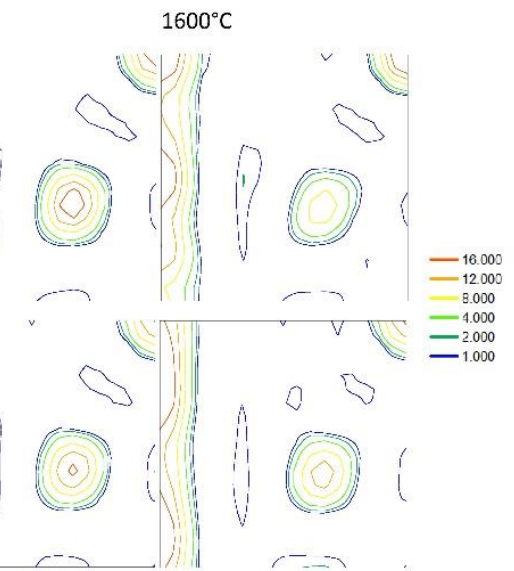

b)

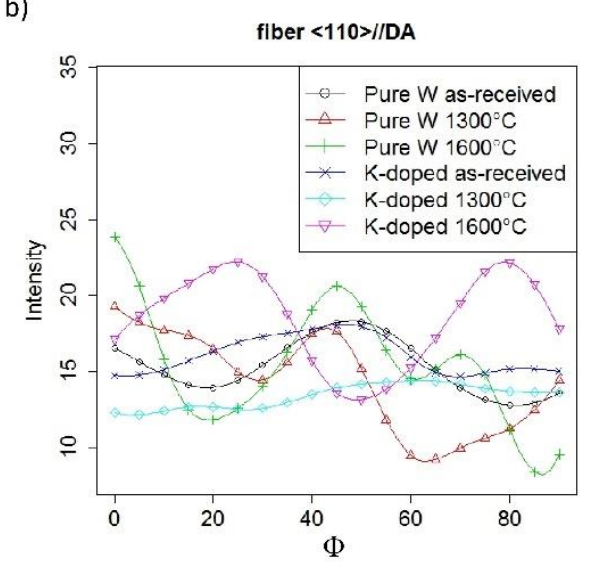

Figure 4: (a) Orientation distribution functions (ODFs) and (b) $<110\rangle$ fiber analysis of the transversal section of both materials up to $1600^{\circ} \mathrm{C} . \varphi_{1}$ and $\Phi$ range from 0 to $90^{\circ} . \varphi_{2}=45^{\circ}$.

As can be seen in Figures 3 and 4, both materials exhibit strong <110>//DA texture with intensities ranging between 10 to 22 for most conditions regardless the annealing temperature, which means that grains with the $<110>/ /$ DA crystallographic direction are 10 to 20 times more likely to be present when compared to any other direction. In the ODFs, Figures $3 \mathrm{a}$ and $4 \mathrm{a}$, the $<110>/ / \mathrm{DA}$ fiber comprises the interval $0 \leq \Phi \leq 90^{\circ}$ for $\varphi_{1}=0$ and $\varphi_{2}=45^{\circ}$ while Figures $3 \mathrm{~b}$ and $4 \mathrm{~b}$ show the variation in the textural intensity of this fiber as a function of the angle $\Phi$. Besides the strong texture observed, one can notice that the K-doped material presents a more homogeneous fiber distribution in comparison with the pure $\mathrm{W}$. This behavior can be linked to the limiting effect of the potassium on recrystallization and grain growth, as shown in the IPF maps of Figures 1 and 2. The steeper microstructural modification in the pure $\mathrm{W}$ material will affect its texture evolution resulting in more heterogeneity along the <110>//DA fiber, although both materials sustain the strong texture up to $1600^{\circ} \mathrm{C}$. The other two areas of larger intensity in the ODFs, the upper right corner $\left(\varphi_{1}=90^{\circ}, \Phi=0^{\circ}, \varphi_{2}=45^{\circ}\right)$ and the region near the center $\left(\varphi_{1}=60^{\circ}, \Phi=55^{\circ}, \varphi_{2}=45^{\circ}\right)$ are very close to the (111) [0 $\left.\overline{1} 1\right]$ and (001) [ $\left.\overline{1} \overline{1} 0\right]$ components, respectively and crystallographically equivalent to orientations present on the $\langle 110\rangle / / \mathrm{DA}$ fiber. The ODFs shown in this study display a similar texture distribution when compared to cold-drawn $\mathrm{Ti}-45 \mathrm{Nb}$ wires in the study conducted by Chen et al.[36], although the latter presents lower intensities for the $\langle 110\rangle$ fiber along the drawing axis. 
The GB maps of Figures 1 and 2 display the boundary network in the wires and show a distinction between randomly oriented (black) boundaries, i.e. any misorientation larger than $5^{\circ}$, and special (red) boundaries that are coincident site lattices (CSLs) from $\Sigma 3$ to $\Sigma 49 \mathrm{c}$ that were determined according to Brandon's criterion from a maximum permissible deviation given by an equation of the form $\Delta \theta=\theta_{0}(\Sigma)^{-}$ ${ }^{\mathrm{n}}$ where $\theta=15$ and $\mathrm{n}=0.5$ [37]. It is known that low- $\Sigma$ CSL boundaries are strongly resistant to fracture in different environments [38]. This is attributed to the fact that grain boundaries occurring in a CSL show a periodic structure and therefore lower energy when compared to random boundaries. $\Sigma$ is the reciprocal density of coincidence sites, e.g. a $\Sigma 9$ boundary is located between two neighboring grains which are misoriented from each other by an angle that results in a coincidence of lattice points of 1/9. If there is more than one misorientation that results in the same fraction of coincidence lattices, different letters are added next to the $\Sigma$ classification. The connectivity of the grain boundaries and the triple junction distributions will be discussed later on.

It is worth mentioning that changes in the color within the grains in the IPF maps as well as changes in the grain boundary character in GB maps, i.e. when a grain boundary line changes its color without interaction with another grain boundary, are related to microstructural heterogeneities resulting from the large plastic deformation to which the wires were exposed during drawing. When plastic deformation is imposed to any polycrystalline material, a number of grains are subjected to the equivalent external stress, but only the ones favorably oriented experience activation of slip systems and subsequent plastic deformation. However, at the same time, neighboring grains that are less favorably oriented will impose restrictions to the deformation compatibility making necessary the rotation of these grains generating dislocations where there are larger misorientations. These rotations are the main cause of deformation heterogeneities resulting in deformation gradients and, hence, gradients in stored energy within and around the grains affecting recovery and recrystallization processes. Depending on the particular grain orientation, different slip systems may be activated inside the same grain resulting in slightly different crystallographic rotations with stable final misorientation within the grain definition i.e. misorientation below $<5^{\circ}$, resulting in color gradients. The strong texture that results from the drawing process is present as expected in the "as-received" conditions [39] and it will play an important role on the evolution of grain boundary character distribution after annealing and is discussed later on.

Both IPF and GB maps clearly show the evolution and the differences between the microstructure of the analyzed materials. Pure W exhibits clearer and faster microstructural modifications when compared to the doped wire. As previously reported, recrystallization and grain growth occur already at $1300^{\circ} \mathrm{C}$ and the grains keep growing up to $1900^{\circ} \mathrm{C}$, but no secondary recrystallization was observed [26]. On the other hand, the K-doped fiber shows minor and homogeneous changes in the microstructure up to $1600^{\circ} \mathrm{C}$, which might be attributed to extended recovery as suggested by Engler and Randle [40] and/or recrystallization as suggested by Zhao et al. [33]. At $2100^{\circ} \mathrm{C}$, a few elongated grains grow much faster than the others consuming the smaller neighboring grains resulting in a bi-modal grain size distribution. Nevertheless, some small grains remain surrounded by larger grains, a clear indication of abnormal grain growth (also called secondary recrystallization). As mentioned before, the main focus of this work is on grain boundaries and triple junction analysis. Any further evaluation related to the samples annealed at $2100^{\circ} \mathrm{C}$ (K-doped material) will refer to regions comprised only by small and elongated grains, like the ones shown in Figure 1. Regarding the annealed condition at $1900^{\circ} \mathrm{C}$ (pure W), some analysis will not be carried out on the transversal section due to the lack of statistical representation since only a few grains and, therefore, few grain boundaries are present.

The reduction of the stored energy caused by deformation as well as the reduction of grain boundary density (length of grain boundaries per area) are the driving force for the recrystallization phenomenon[19,41] and, as pointed out qualitatively on the GB maps of Figure 1, it occurs faster in pure $\mathrm{W}$. This behavior is a clear indication of the effectiveness of potassium in suppressing the grain boundary mobility[42]. For a quantitative comparison, Figures $5 \mathrm{a}$ and $5 \mathrm{c}$ display a steeper reduction of the grain boundary density in pure $\mathrm{W}$ fibers in comparison with the K-doped material on both inspected 
c)

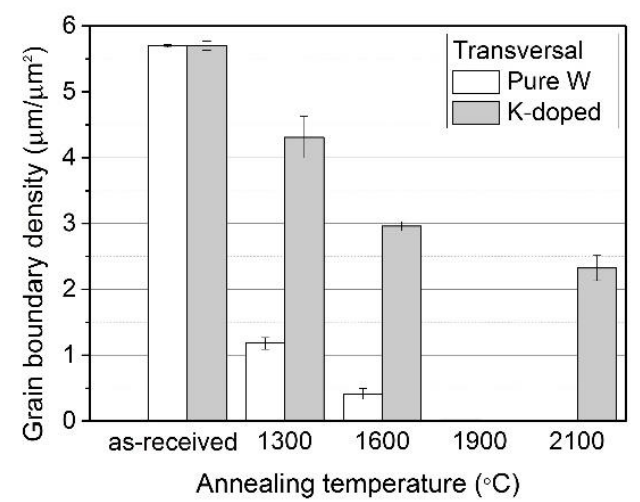
longitudinal and transversal sections, respectively.

a)

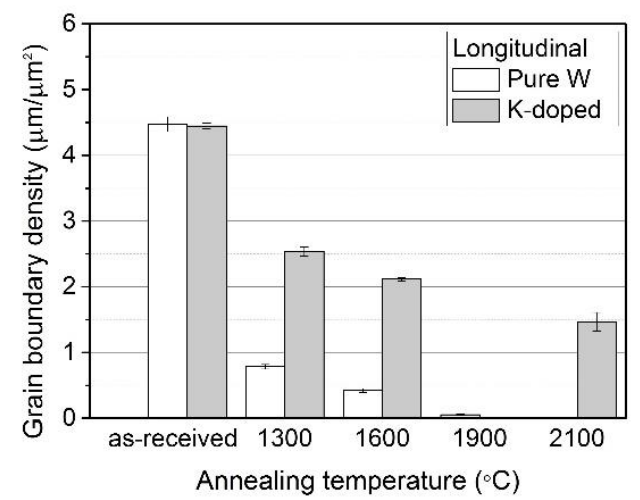

sections i.e. longitudinal and transversal ones, respectively. Comparing different materials at the same annealing temperature, the boundary density is always lower on the longitudinal section as a consequence of the characteristic morphology of drawn materials: i.e. the very elongated grains. The anisotropy of the grain shape results in anisotropy of the grain boundary density. Figures $5 \mathrm{~b}$ and $5 \mathrm{~d}$ show the grain boundary character distribution (GBCD), i.e. the fractions of low-angle grain boundaries (LAGB - misorientation angles between 5 and $15^{\circ}$ ), CSL boundaries and high-angle grain boundaries (HAGB - misorientation angles larger than $15^{\circ}$ ) as a function of the annealing temperature on the

b)

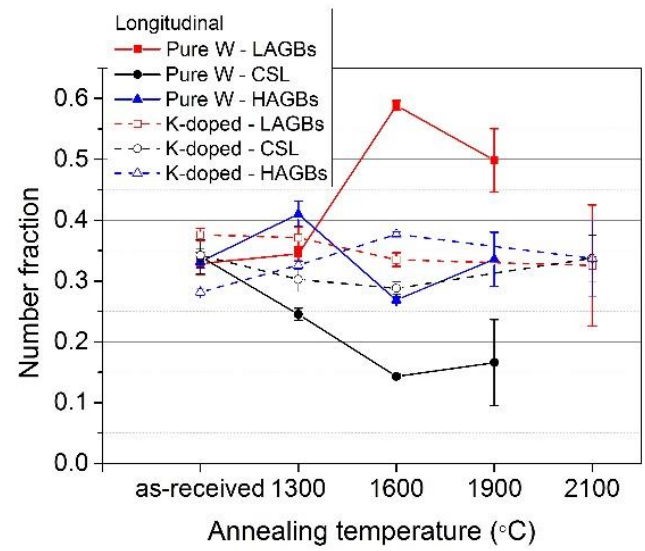

d)

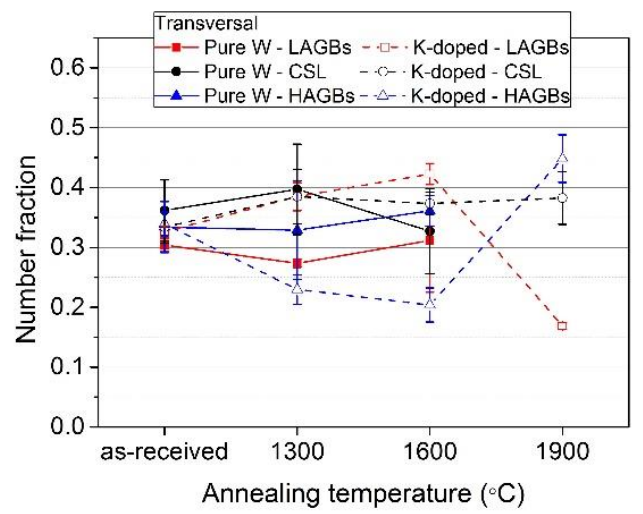

Figure 5: (a) and (c) Grain boundary densities and (b) and (d) grain boundary character distributions of pure W and K-doped materials as function of annealing temperature. (a) and (b): longitudinal section. (c) and (d) transversal section.

Figure $5 b$ shows fewer variations on the GBCD of the K-doped samples upon annealing which confirms the observations on the grain shape/size behavior. The more difficult it is to change the microstructure the less variation on GBCD one should expect. The as-received conditions exhibit similar GBCD, since the manufacturing processes for both materials were the same. Upon annealing the differences can be identified. For the K-doped wires, on the longitudinal section, the fractions of LAGB, CSL and HAGB remain approximately equal to each other (between 0.3 and 0.4 ) regardless the annealing temperature. The pure $\mathrm{W}$ exhibits an increase in the LAGB, reduction on CSL while the HAGB fraction oscillated between $0.25-0.40$. When compared to other conventional low deformation processes such as rolling and forging, a relevant feature is the relatively large fraction of HAGB in materials that underwent severe plastic deformation as can be seen in all conditions, regardless of the analyzed section. According to Hughes and Hansen [43], who studied the effect of large strains on Aluminum, Nickel and Tantalum, this behavior is ascribed to deformation induced high-angle boundaries and relies on continued grain subdivision into crystallites surrounded by dislocation boundaries resulting in a large misorientation 
spread based on dislocation accumulation processes. Different slip system combinations can lead to the formation of complex dislocation structures inside individual crystallites. As a result, parts of the grain may rotate towards different stable end orientations. Similar observations were made in a study conducted by Nikolić et al. [28] on the same material. Alternatively, in the transversal section, Figure $5 \mathrm{~d}$, differences on the fractions of GBCD with the annealing temperature are not as large as in the longitudinal section. This behavior can be ascribed to the slender reduction of grain boundary densities compared to the longitudinal section. These differences will require the evaluation of a possible anisotropic effect on the CSL, as well as in the triple junctions distributions along perpendicular sections.

Another behavior that must be pointed out is the increase of the LAGB fractions with increasing annealing temperature. In the present work, this feature was observed in the longitudinal section of the pure $\mathrm{W}$ material and in the transversal section of the K-doped samples. Also according to Hughes and Hansen[43], this can be explained by orientation pinning that can slow down or even stop the migration of a HAGB. It happens when a growing grain meets a deformed crystallite with similar orientation causing the replacement of the highly mobile HAGB by a much less mobile LAGB. As reported in our previous study[26] and also shown in Figures 3 and 4, the $\langle 110\rangle$ texture parallel to the drawing axis of both materials remained fairly strong around 10-20 times random regardless the annealing temperature, which explains the GBCD behavior.

Figures 6 and 7 display misorientation distributions of the samples in the longitudinal and transversal section, respectively. On the one hand, the misorientation distribution function (MDF) is measured considering the misorientations $g_{i j}$ between all grains $i$ and all their first neighbor $j$ displaying the "real" misorientation of the microstructure. On the other hand, the orientation difference distribution function (ODDF) is directly derived from the ODF (Figures 3a and 4a) as it is calculated under the assumption of a random arrangement of the orientations in the microstructure. It can be noted that the standard Mackenzie distribution, which is the misorientation angle distribution in totally random oriented polycrystals (i.e. texture-free), plotted as a dashed line in the Figures 6(a) and 7(a), is different from the ODDF distributions. This difference resides in the texture itself: while Mackenzie is valid for a random orientation distribution, ODDF is derived for a given texture assuming its random topological arrangement. To identify features that arise from a given local arrangement and the features controlled by the texture, the locally measured misorientation, MDF, must be normalized by the ODDF resulting in the orientation correlation function (OCF). Therefore, the OCF-value is a texture-reduced spatial correlation of misorientations and indicates a higher $(\mathrm{OCF}>1)$ or lower $(\mathrm{OCF}<1)$ frequency when compared to a statistically-expected arrangement of grains. 
a)

As-received
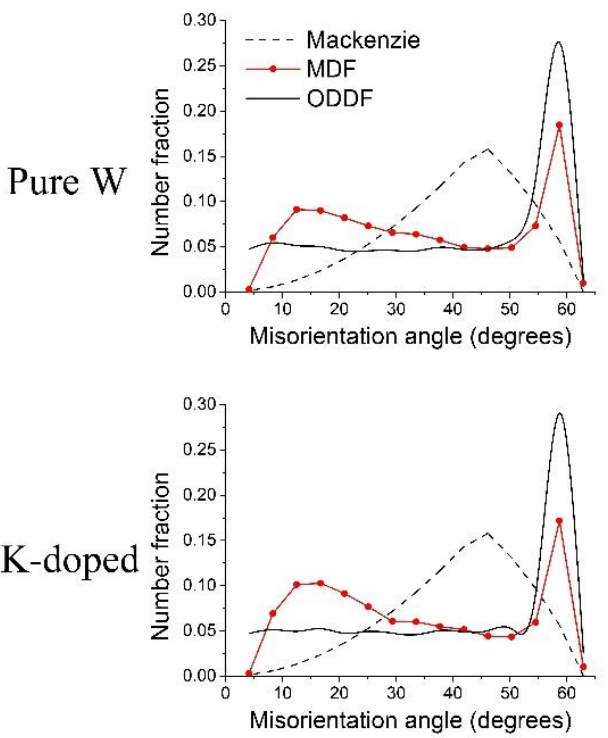

$1300^{\circ} \mathrm{C}$
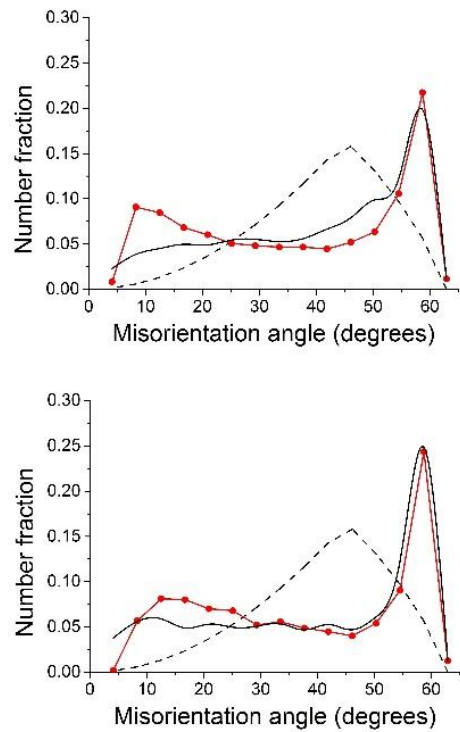

$1600^{\circ} \mathrm{C}$
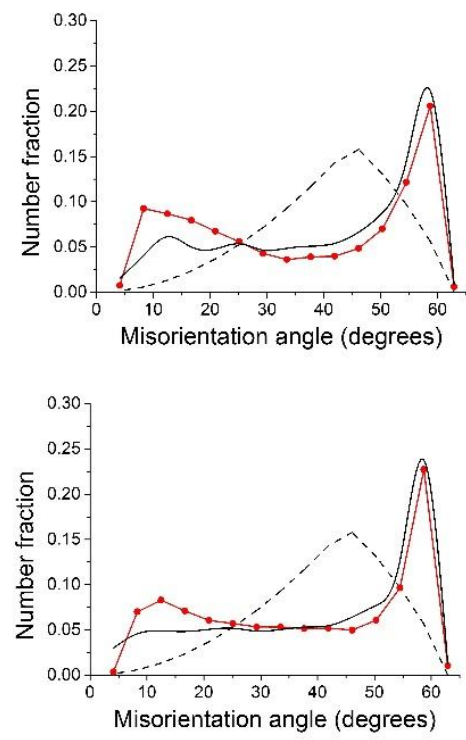

b)

c)
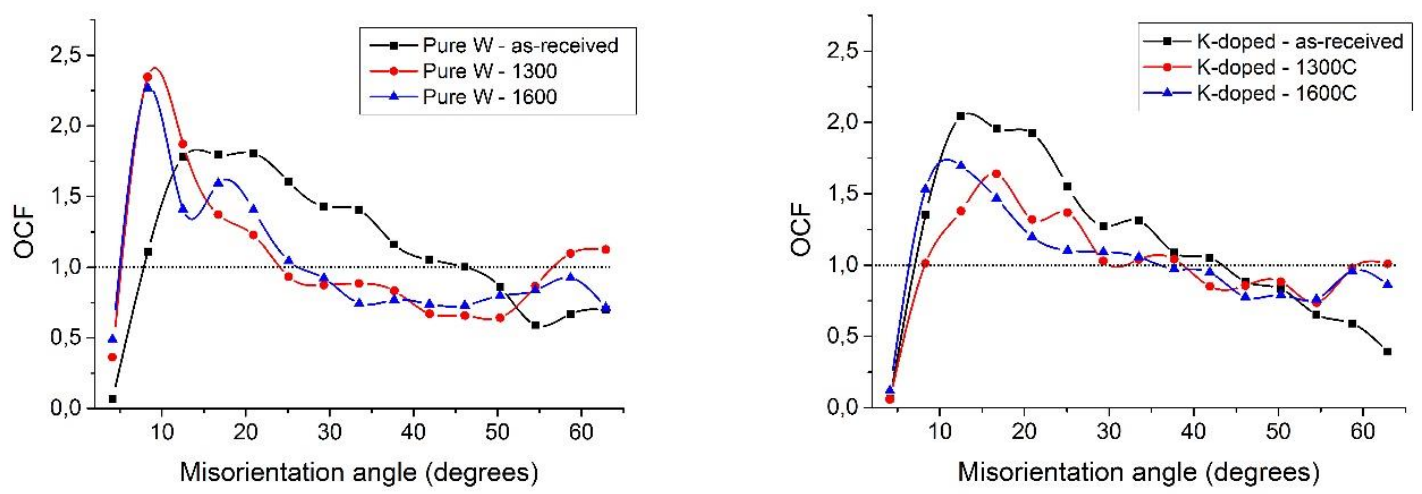

Figure 6: Longitudinal misorientation angle distributions: (a) measured misorientation distribution functions (MDFs), (b) orientation correlation function (OCF) for the pure $\mathrm{W}$ and (c) OCF for the Kdoped material. 
a)

As-received
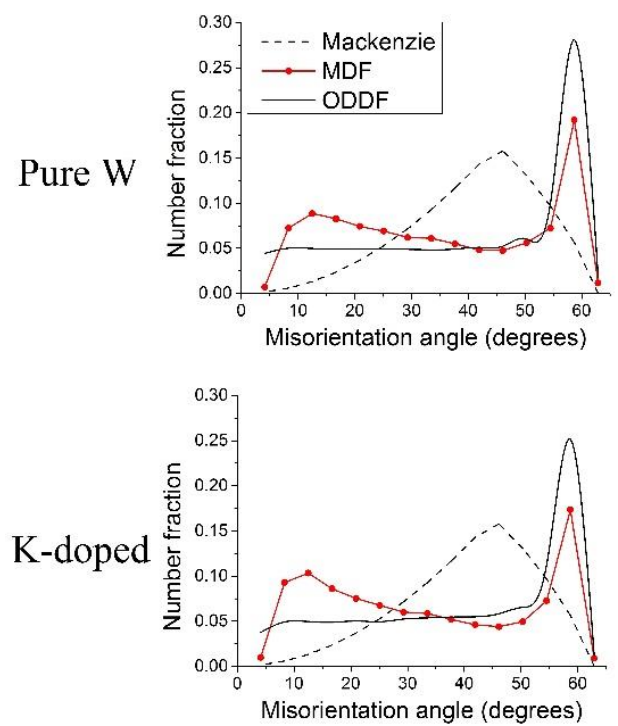

299

b)

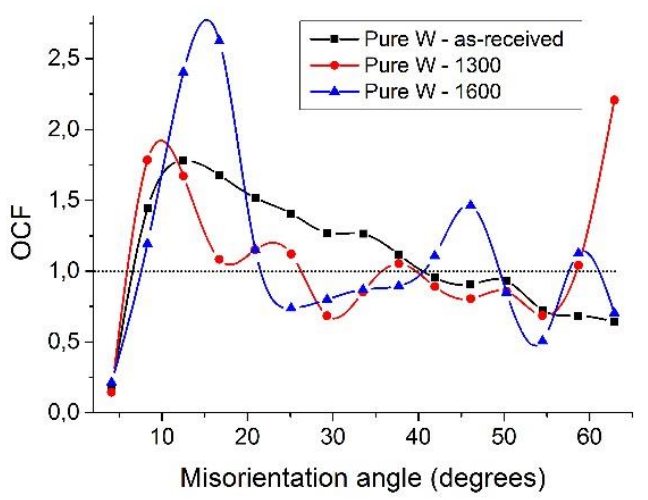

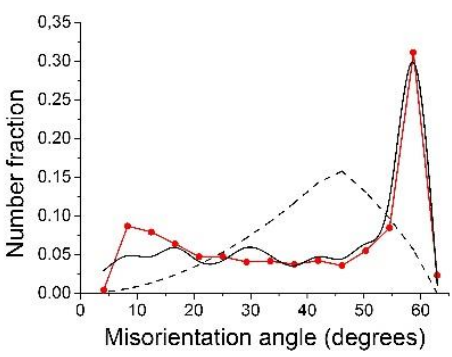
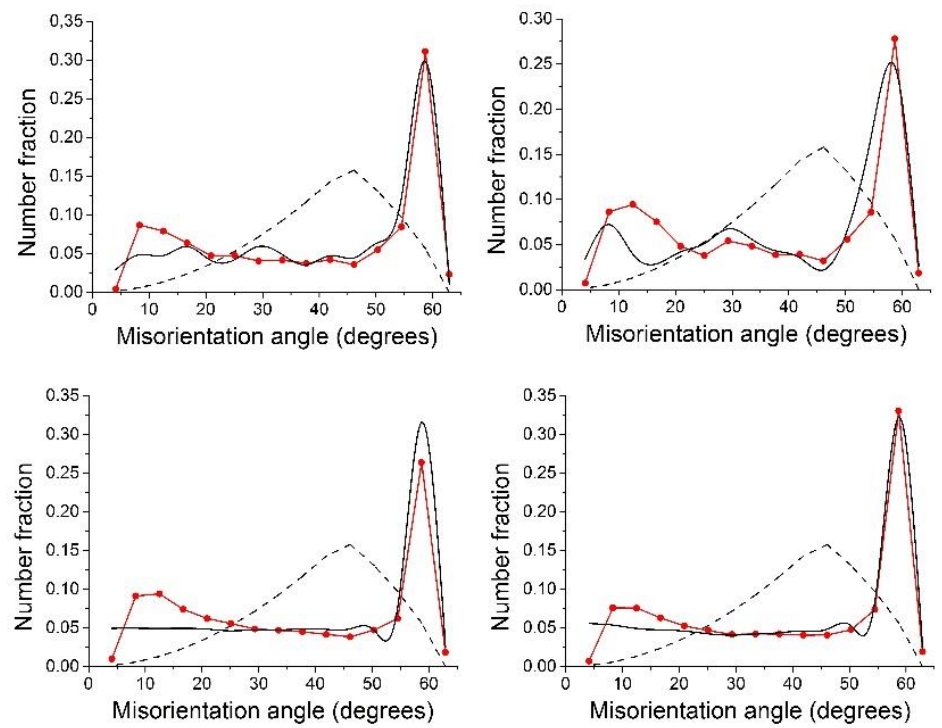

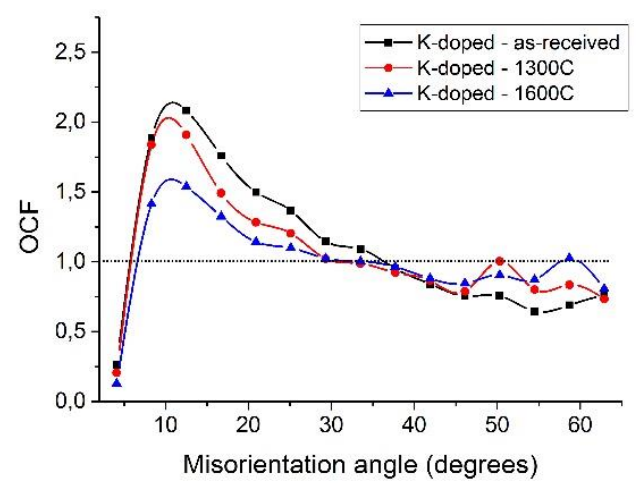

Figure 7: Transversal misorientation angle distributions: (a) measured misorientation distribution functions (MDFs), (b) orientation correlation function (OCF) for the pure $\mathrm{W}$ and (c) OCF for the Kdoped material.

As can be seen in Figures $6 \mathrm{~b}, 6 \mathrm{c}, 7 \mathrm{~b}$ and $7 \mathrm{c}$, OCF values tend to be larger than 1 for the lower angle misorientations, i.e. below $20^{\circ}$. Consequently, for higher misorientation angles, OCF values tend to become lower than 1 . This result indicates that low-angle grain boundaries are more frequently occurring than they would be in a sample with the same crystallographic texture but random spatial arrangement of the orientations. This feature points out that recrystallization occurs by continuous sub-grain coarsening, also called extended recovery or continuous recrystallization. This mechanism was also suggested by Lied et al. [44] to occur during recrystallization of pure and K-doped cold-rolled W sheets.

As the annealing temperature increase, and grain growth takes place, the OCF values tend to become more homogeneous and remain closer to 1 for all misorientation angles in the case of the K-doped material, reducing the predominance of the sub-grain coarsening mechanism during grain growth. Similar OCF-analysis was performed by Engler and Huh [45] to study texture evolution in high purity aluminum foils. However, in their work, significant higher OCF-values confirmed the occurrence of sub-grain coarsening mechanism during grain growth.

A closer look at the $\Sigma$ boundaries distributions revealed a set of more frequently occurring special boundaries as well as the effect of the annealing temperatures on them. Figure 8 is an example given for 
the longitudinal section of the K-doped material. For comparison, random CSL distribution data are plotted in green and labeled as "Random pure W" belonging to a texture-free tungsten produced via spark plasma sintering [46].

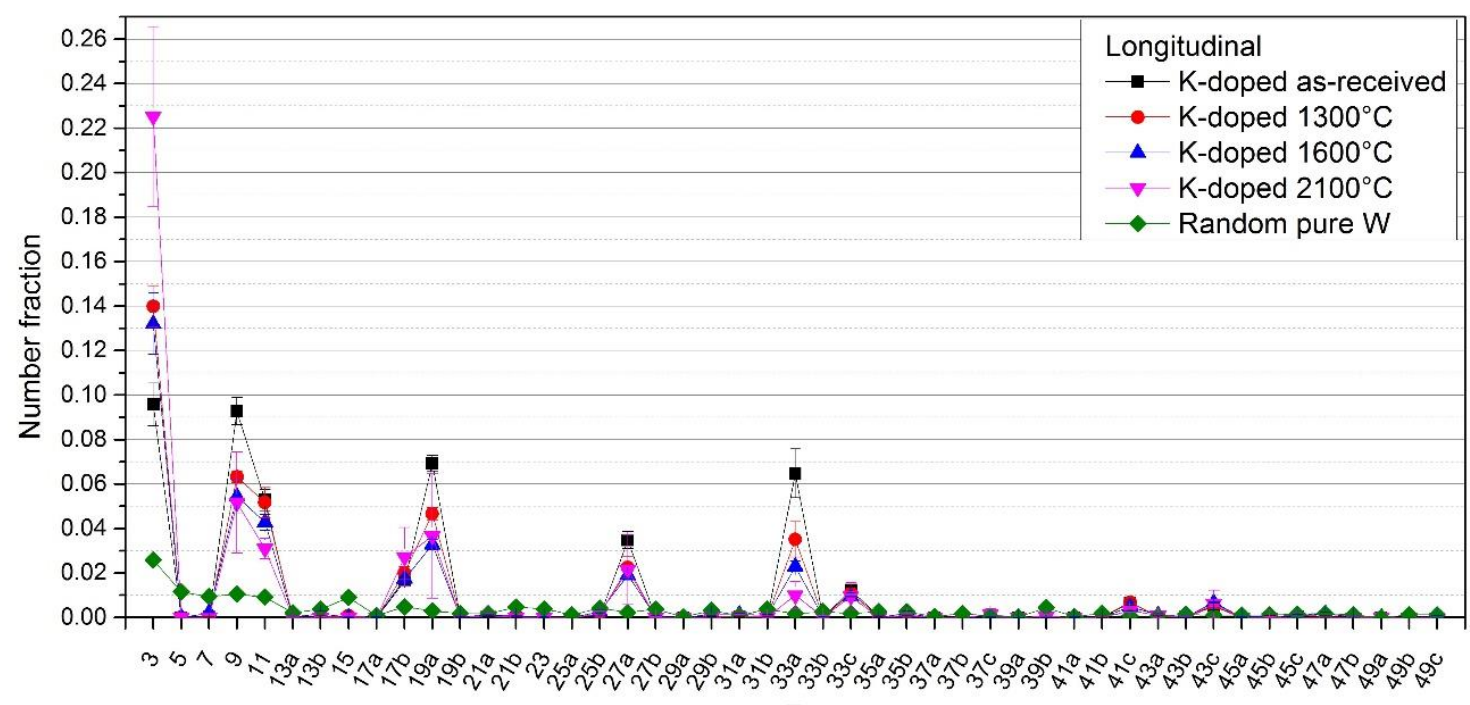

Figure 8: $\Sigma$ CSL boundaries distribution of K-doped fibers in the as-received and annealed conditions.

Both materials present very similar CSL distributions irrespective of the analyzed section (that is why the authors decided to show only one distribution as an example) with common components at $\Sigma 1$ (i.e. LAGB), $\Sigma 3, \Sigma 9, \Sigma 11, \Sigma 17 \mathrm{~b}, \Sigma 19 \mathrm{a}, \Sigma 27 \mathrm{a}, \Sigma 33 \mathrm{a}, \Sigma 33 \mathrm{c}, \Sigma 41 \mathrm{c}$ and $\Sigma 43 \mathrm{c}$. Among these $\Sigma$ values, 33c, 41c and $43 \mathrm{c}$ are present in negligible fractions (less than 0.01 ). As the annealing temperature goes up, there is a general trend on increasing $\Sigma 3$ boundaries fractions while all the other CSL fractions are reduced. If one considers the " $\Sigma 3$ regeneration model" proposed by Randle[47] to describe the interaction between boundaries at triple junctions (TJ) and the formation of $\Sigma 3$ through the reaction $\Sigma 3^{\mathrm{n}}+\Sigma 3^{(\mathrm{n}+1)}$ $\rightarrow \Sigma 3$ (mainly used for FCC and low stacking fault energy materials), it seems to be applicable for the tungsten wires as well. Although tungsten is a BCC metal with elevated stacking fault energy[48], the fractions of $\Sigma 9$ and $\Sigma 27$ a were reduced while $\Sigma 3$ has increased. There seems to be no anisotropy on the evolution of the CSL fraction $(3 \leq \Sigma \leq 49)$ distributions since the values for transversal and longitudinal sections evolve in a similar way with the annealing temperature increase.

Some studies on other BCC metals [38,49] have shown and linked the $\Sigma 1, \Sigma 3, \Sigma 9, \Sigma 11, \Sigma 19$ and $\Sigma 27$ CSL boundaries to the $\langle 110\rangle$ texture in $\mathrm{Fe}-6.5 \% \mathrm{Si}$ ribbons. These studies have taken into account a different range of CSL ( $\Sigma 3-\Sigma 29)$. Watanabe et al. [38] proposed an empirical law to describe the fraction of CSL boundaries with specific $\Sigma$ values in order to precisely predict the fraction of a given boundary. It was found that the incidence of low- $\Sigma$ CSL boundaries $(3 \leq \Sigma \leq 29)$ tends to increase with descending order of $\Sigma$-value in sharply $\{100\}$ and $\{110\}$ textured Fe-6.5\% Si ribbons. According to their observations, the fraction of low- $\Sigma$ CSL boundaries, $\mathrm{F}_{\Sigma}$, is proportional to the inverse cubic root of the $\Sigma$-value as follows:

$$
F_{\Sigma}=K \Sigma^{-1 / 3}+F_{0}
$$

Where $\mathrm{K}$ and $\mathrm{F}_{0}$ are constants which may depend on thermal history of the material. Figures $9 \mathrm{a}$ and $9 \mathrm{~b}$, show the inverse cubic root correlation based on the longitudinal data for pure $\mathrm{W}$ and $\mathrm{K}$-doped wires, respectively, while Figures $9 \mathrm{c}$ and $9 \mathrm{~d}$ display the same analysis based on the transversal section data. 
a)

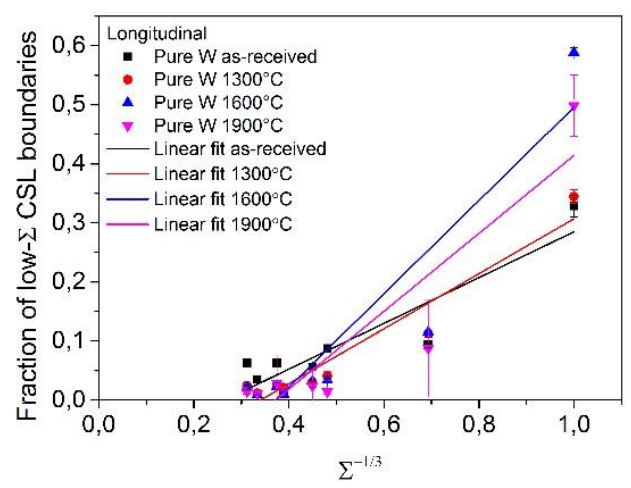

c)

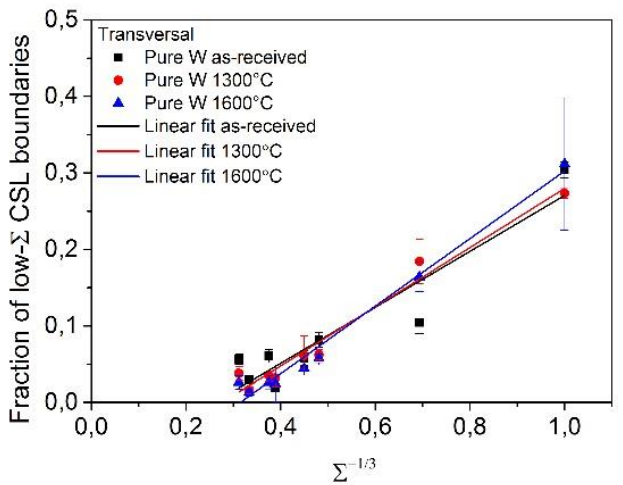

b)

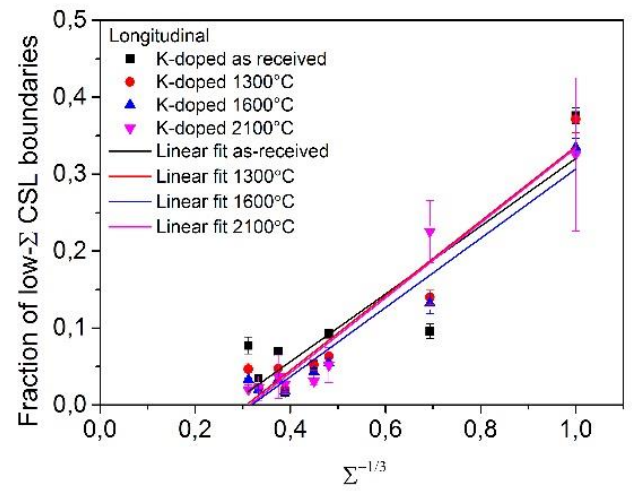

d)

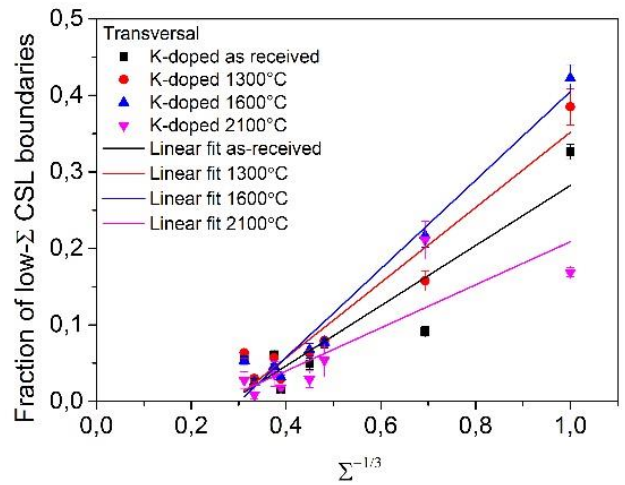

351

352

353

354

355

356

357

Figure 9: The inverse cubic root $\Sigma$ dependence of the low- $\Sigma$ CSL fraction of (a) and (c) pure W and (b) and (d) K-doped wires. (a) and (b) longitudinal sections (c) and (d) transversal sections.

Table 2 summarizes the calculated parameters extracted from the linear fit of the experimental data presented in Figure 9 together with the Pearson's r coefficient. The better the model fits data the closer to unity the Pearson's r coefficient will be.

Table 2: Parameters of the inverse cubic root $\Sigma$ equation.

\begin{tabular}{|c|c|c|c|c|c|c|c|c|}
\hline & \multicolumn{4}{|c|}{ Pure W } & \multicolumn{4}{|c|}{ K-doped } \\
\hline \multicolumn{9}{|c|}{ Longitudinal } \\
\hline & $\begin{array}{l}\text { As- } \\
\text { received }\end{array}$ & $1300^{\circ} \mathrm{C}$ & $1600^{\circ} \mathrm{C}$ & $1900^{\circ} \mathrm{C}$ & $\begin{array}{l}\text { As- } \\
\text { received }\end{array}$ & $1300^{\circ} \mathrm{C}$ & $1600^{\circ} \mathrm{C}$ & $2100^{\circ} \mathrm{C}$ \\
\hline $\mathrm{F}_{0}$ & -0.1025 & -0.1585 & -0.2938 & -0.2455 & -0.1200 & -0.1493 & -0.1435 & -0.1531 \\
\hline $\mathrm{K}$ & 0.3874 & 0.4654 & 0.7896 & 0.6596 & 0.4403 & 0.4852 & 0.45 & 0.4870 \\
\hline $\begin{array}{l}\text { Pearson's } \\
\text { r }\end{array}$ & 0.92 & 0.96 & 0.93 & 0.92 & 0.90 & 0.96 & 0.97 & 0.98 \\
\hline \multicolumn{9}{|c|}{ Transversal } \\
\hline $\mathrm{F}_{0}$ & -0.0954 & -0.1072 & -0.1391 & - & -0.1108 & -0.1397 & -0.1744 & -0.0727 \\
\hline $\mathrm{K}$ & 0.3659 & 0.3869 & 0.4415 & - & 0.3931 & 0.4915 & 0.5795 & 0.2814 \\
\hline $\begin{array}{l}\text { Pearson's } \\
\text { r }\end{array}$ & 0.94 & 0.99 & 0.99 & - & 0.92 & 0.97 & 0.98 & 0.86 \\
\hline
\end{tabular}

According to Table 2, all conditions exhibit a Pearson's coefficient larger than 0.90 (the only exception was the transversal section of the K-doped material annealed at $2100^{\circ} \mathrm{C}$ ). The condition with the best linear fit is the transversal section of the pure W. These results are in good agreement with Watanabe's prediction. With increasing annealing temperature, the $\mathrm{K}$ values (the slope of the line) tend to increase while $\mathrm{F}_{0}$ values tend to decrease. 
It needs to be mentioned that the morphology of grains and grain boundaries plays an important role in the evolution of plastic deformation of metals under external load. In particular, the character of grain boundaries will determine the interaction of dislocations with and their ability to be absorbed by or be transmitted through grain boundaries. Subsequently, the build-up of stress concentrations near grain boundaries and initiation of cracks will depend on the character of grain boundaries. It has been shown that low-energy grain boundaries are resistant to fracture for polycrystalline metals in different environments. Randomly oriented boundaries were found to act as preferential sites for crack nucleation and its subsequent propagation. Since the low-temperature embrittlement (i.e. near the onset of the plastic deformation) in polycrystalline materials is caused primarily by intergranular fracture[38], increasing the fraction of "special" low- $\Sigma$ (CSL) boundaries might help to improve fracture strength, and this benefit must be assessed in the context of triple junctions (TJ) and grain boundary connectivity. As the EBSD data is acquired through a hexagonal grid of pixels, as can be noticed in Figure 10, this is an ideal input to identify the intersection of three hexagons i.e. the TJ itself. As important as the CSL fraction, the connectivity of the grain boundary networks that are susceptible to failure must be reduced in order to increase the ductility and fracture toughness of the material.

The connectivity of grain boundaries is assessed through the analysis of TJ nodes since these can act as a crack arrester or a crack assister. Figure 10 displays an IPF map of the K-doped material annealed at $2100^{\circ} \mathrm{C}$ to exemplify the four types of TJ nodes, combinations of random boundaries (R) and special (S) CSL boundaries next to each other, i.e. 0-CSL, when all three grain boundaries at the TJ are random (RRR - white circle 1), 1-CSL, when one of the boundaries is a CSL and the other two are random (RRS - white circle 2), 2-CSL, when two CLS boundaries are present and the third boundary is random (RSS - white circle 3) and, finally, 3-CSL, when all three boundaries are CSL (SSS - white circle 4).

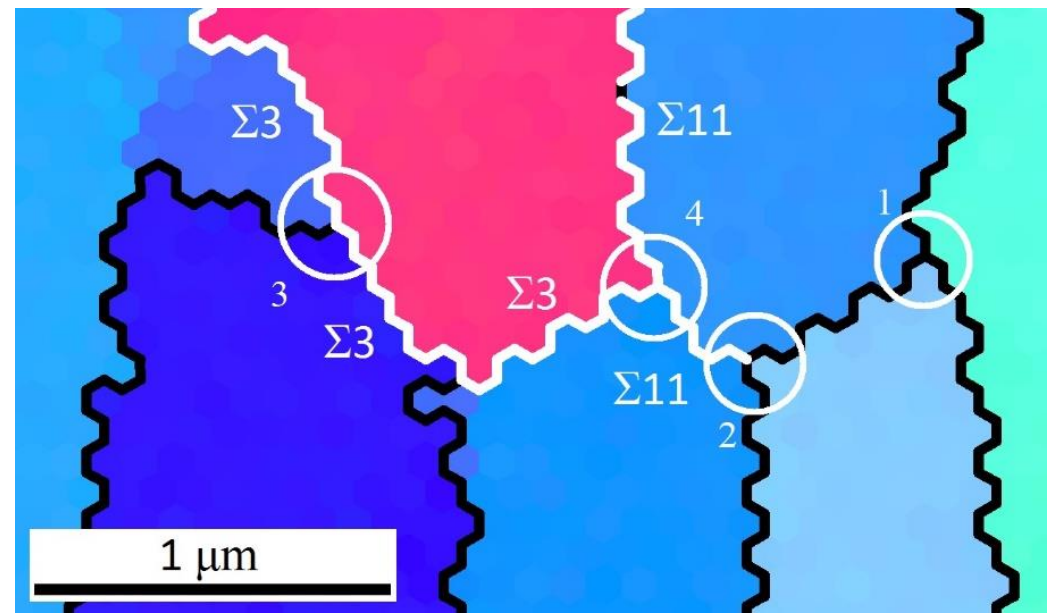

Figure 10: IPF map of the K-doped material annealed at $2100^{\circ} \mathrm{C}$ showing the four different types of TJ nodes inside the white circles: 1 (RRR), 2 (RRS), 3 (RSS) and 4 (SSS). Black lines are random boundaries $(\mathrm{R})$ and white lines are CSL boundaries.

The last type of the TJ node (white circle number 4), $\Sigma 3-\Sigma 11-\Sigma 11$, does not obey the suggested "rules" of TJ combination and would not be possible in unstressed crystals where no deviations from ideal CSL are allowed. The formula $\Sigma_{3}=\Sigma_{1} \Sigma_{2} / \beta^{2}$, where one of the $\Sigma$ 's (e.g. $\Sigma_{3}$ ) is always larger than the other two and $\beta$ is a common divisor of $\Sigma_{1}$ and $\Sigma_{2}$, is not obeyed [50]. Frary and Schuh[51] have also proposed a "deviation limit rule" in order to extend the previous "combination rule" taking into account the deviations from the ideal CSL positions. They proposed that the largest deviation of any boundary from an ideal CSL misorientation should not exceed the sum of the deviations of the other two boundaries in 
the same TJ. Here, this is not the case either, since the deviations are $1.7,4.0$ and $7.0^{\circ}$, which means that this TJ cannot be predicted by the known rules.

401

402

403

404

405

406

407

408

409

410

411

412

413

c)

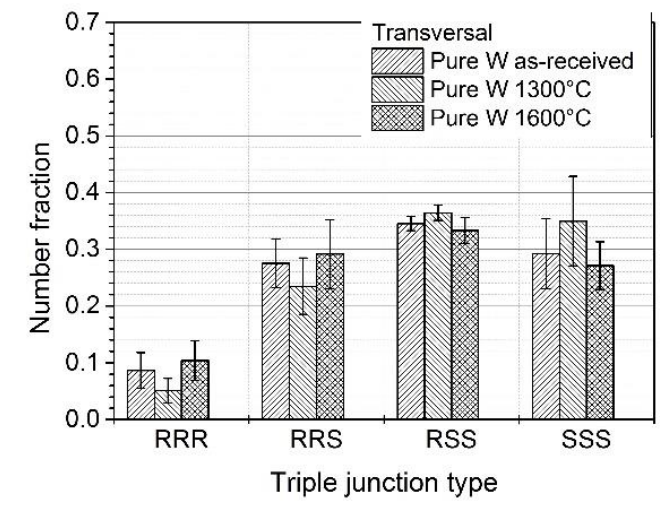
transversal and longitudinal sections.

a)

The distributions of the TJ nodes in the analyzed samples are shown in Figure 11. Here the LAGB fractions are taken into account as the low- $\Sigma$ CSL " $\Sigma 1$ ". Focusing the analysis on the annealing temperatures up to $1600^{\circ} \mathrm{C}$, to exclude heterogeneous microstructures, one can notice different behavior when different sections of the same material are compared. In other words, there is anisotropy with respect to the TJ node distributions. In the longitudinal sections, with the increase of the annealing temperature, the fraction of RRR and RRS types of nodes increases whereas the fraction of SSS nodes decreases. In pure W samples, the RSS percentage decreases while it remains constant in the K-doped samples. Analyzing the transversal sections and taking into account the standard deviation intervals, the pure $\mathrm{W}$ displays constant values for all four types of TJ nodes irrespective of the annealing temperature. The microstructure of the K-doped wires exhibits a reduction of the fractions of the RRR and RRS nodes and subsequent increase of SSS nodes. The fraction of RSS nodes remains constant as observed on both

b)

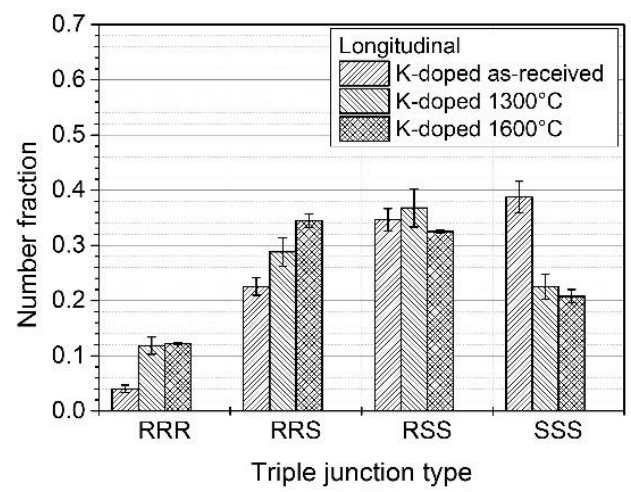

d)

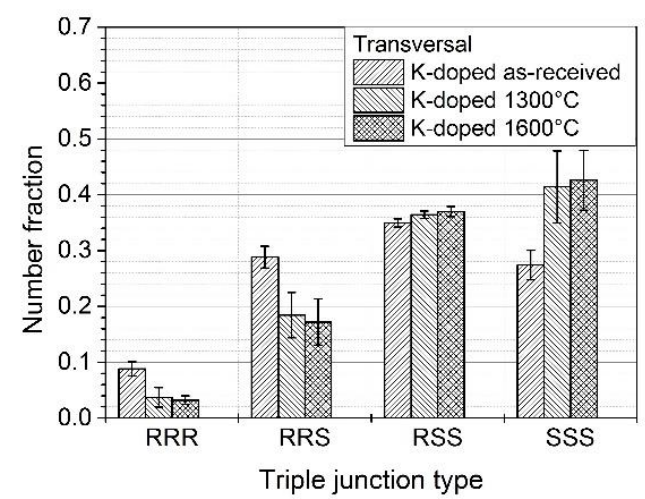

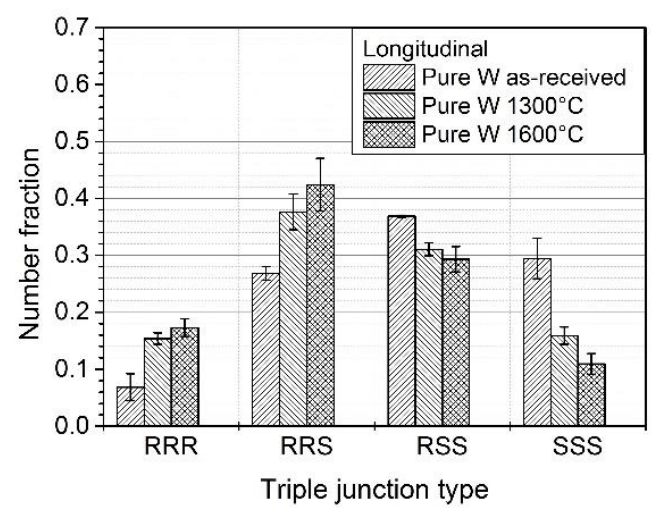

Figure 11: Triple junction (TJ) distribution of (a) and (c) pure W and (b) and (d) K-doped material. (a) and (b) longitudinal section. (c) and (d) transversal section.

The connectivity of TJs, in terms of the character of grain boundaries involved, plays an important role in determination of the local plasticity under externally applied load. As noticed earlier, depending on the character of the TJ node it may act as either a crack assister (i.e. prevent plastic deformation and cause an increase of stress concentration) or a crack arrester (i.e. facilitate the propagation of plastic deformation from one grain to another). In order to analyze and evaluate the microstructural resistance, only the TJ nodes that comprise at least one boundary that is susceptible to cracking will be taken into account, i.e. RRR, RRS and RSS, since the SSS TJ are inactive entities on arresting or assisting the crack propagation (based on the assumption that the crack front would never approach this type of TJ). 
Among the four types of TJ nodes presented, when at least two low- $\Sigma$ CSL are present (i.e. RSS) the connectivity of random boundaries will be broken as well as the path of intergranular crack extension. According to King et al.[52], percolative paths in the microstructure will be broken if the following equation holds:

$$
\mathrm{f}_{2 \mathrm{CSL}} / \mathrm{f}_{(1-3 \mathrm{CSL})} \geq 0.35
$$

where $\mathrm{f}_{2 \mathrm{CSL}}$ is the fraction of RSS TJ nodes and $\mathrm{f}_{(1-3 \mathrm{CSL})}$ is the fraction of TJ nodes that are composed by at least one randomly oriented boundary (i.e. 1 minus the SSS TJ nodes fraction) in the microstructure. This ratio represents the fraction of $\mathrm{TJ}$ nodes that are resistant to intergranular crack propagation. Figure 12 shows these fractions for the studied samples up to $1600^{\circ} \mathrm{C}$ in both scanned cross-sections. Different trends can be noticed depending on the analyzed section.

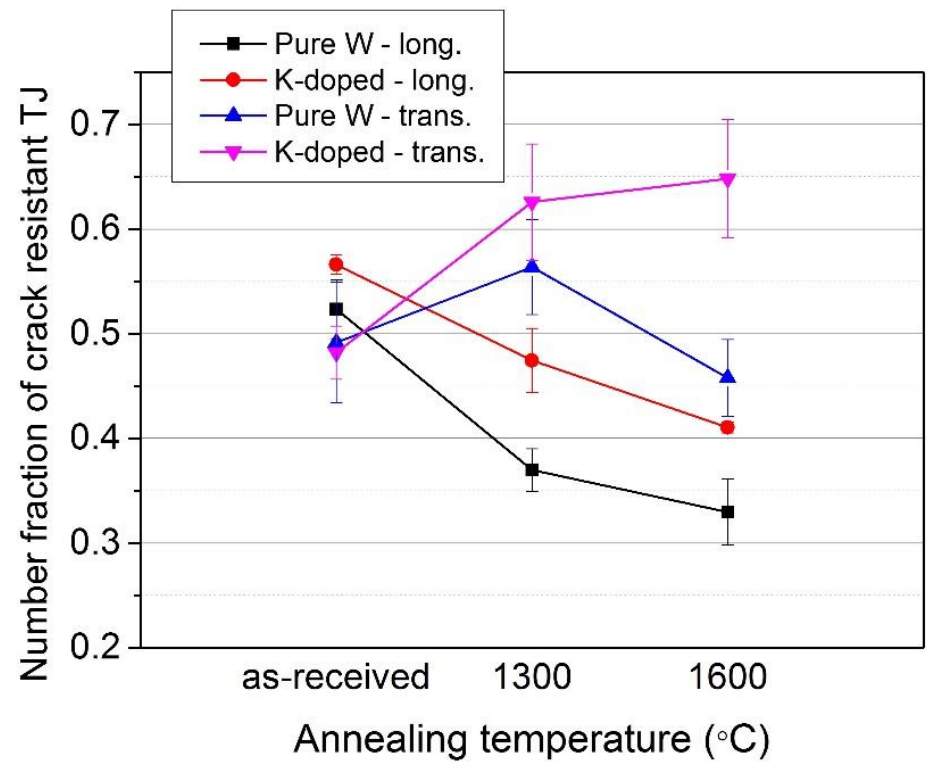

Figure 12: Number fraction of resistant intergranular crack triple junctions as a function of the annealing temperature.

The results obtained at the annealing temperature of $1900^{\circ} \mathrm{C}$ and higher have reduced statistical significance due the small number of TJs available for the EBSD analysis, therefore they were not presented.

In our previous work, where the transversal section of the K-doped material was analyzed [53], a different range of CSL boundaries was taken into account $(3 \leq \Sigma \leq 29)$ but the increase of the intergranular crack propagation resistance was observed. In the current study, the same trend is observed and a relevant anisotropic aspect can be noticed, namely: with increasing the annealing temperature the resistance of TJ nodes on the transversal section to intergranular crack propagation enhances but, at the same time, it is reduced in the longitudinal section. This statement is valid for the $\mathrm{K}$-doped samples annealed at temperatures at which statistically relevant data could be obtained. Thus, by increasing the annealing temperature there might be a larger probability of intergranular fracture across longitudinal TJ nodes. This anisotropic effect is preserved up to a higher annealing temperature in the K-doped material since the difference of resistance between both sections becomes larger at $1600^{\circ} \mathrm{C}$ while it is reduced for pure W. Such behavior is apparently linked to the microstructure of elongated grains that is retained up to higher annealing temperatures in the K-doped material thanks to the suppressing of grain boundary mobility. These findings are in accordance with a recent study of Pfeifenberger et al.[18], where they investigated the intergranular cracking resistance of ultrafine grained tungsten materials and 
of diameter (similar to the ones used in the present study). For both materials, intergranular fracture prevailed along the weaker direction, parallel to the needle-like shape of the grains, i.e. in the longitudinal surface.

\section{Conclusions}

In the present study, the analysis of microtexture, grain boundary character and distribution of triple junction types was carried out in pure and potassium doped drawn tungsten wires annealed at different temperatures, which represent technological relevance for fusion operational conditions. Both longitudinal and transversal sections were investigated to assess anisotropic aspects of the grain structure.

Both materials, in all conditions, exhibited a strong <110>//DA texture regardless the annealing temperature, while with increasing annealing temperature, the K-doped material presented a more homogeneous fiber distribution as compared to the pure $\mathrm{W}$.

An analysis of the orientation correlation function (OCF) showed that small misorientation angles play an important role during recrystallization suggesting recrystallization occurs by continuous sub-grain coarsening, which is sometimes also called extended recovery or continuous recrystallization. This mechanism was, however, clearly less pronounced during grain growth of the K-doped material.

A large fraction of high-angle grain boundaries was observed in the as-received condition for both studied materials and its reduction at the expense of the emergence of low-angle grain boundaries was observed under annealing with the progressively increasing temperature. No significant differences were noted with respect to the evolution of coincident site lattices boundary between the longitudinal and transversal sections. The predominant types of CSL boundaries were: $\Sigma 1, \Sigma 3, \Sigma 9, \Sigma 11, \Sigma 17 \mathrm{~b}, \Sigma 19 \mathrm{a}$, $\Sigma 27 \mathrm{a}, \Sigma 33 \mathrm{a}$ and a good correspondence with the empirical law of the inverse cubic root $\Sigma$ dependence of the GB fraction was found.

The analysis of the character of triple junctions evidenced an anisotropic distribution. The increase of the annealing temperature led to the emergence of the TJ nodes that might be able to improve the resistance to intergranular crack propagation in the transversal section, while at the same time it yielded the increase of TJ nodes that can suppress crack resistance in the longitudinal section. Progressive annealing, from the TJ analysis point of view, could lead to the increase on crack deflection probability since the difference on intergranular cracking resistance, when comparing transversal and longitudinal sections, increase up to 1300 and $1600^{\circ} \mathrm{C}$ for pure tungsten and $\mathrm{K}$-doped material, respectively.

\section{Acknowledgements}

This work has been carried out within the framework of Erasmus Mundus International Doctoral College in Fusion Science and Engineering (Fusion-DC) and the EUROfusion Consortium. This project has received funding from the Euratom research and training programme 2014-2018 and 2019-2020 under grant agreement No 633053. The views and opinions expressed herein do not necessarily reflect those of the European Commission or of the ITER Organization. The authors want to acknowledge support by Osram $\mathrm{GmbH}$, Schwabmünchen, Germany for providing the tungsten wire and performing the annealing.

\section{Data Availability}

The raw/processed data required to reproduce these findings cannot be shared at this time as the data also forms part of an ongoing study.

\section{References}


[1] Meinshausen M, Meinshausen N, Hare W, Raper SCB, Frieler K, Knutti R, et al. Greenhousegas emission targets for limiting global warming to 2 C. Nature 2009;458:1158-62. doi:10.1038/nature08017.

[2] Cox PM, Betts RA, Jones CD, Spall SA, Totterdell IJ. Acceleration of global warming due to carbon-cycle feedbacks in a coupled climate model. Nature 2000;408:184-7.

[3] Key World Energy Statistics. 2016.

[4] ITER 2019. https://www.iter.org/.

[5] Velasquez CE, Pereira C, Veloso MAF, Costa AL, de P. Barros G. Fusion-Fission Hybrid Systems for Transmutation. J Fusion Energy 2016;35:505-12. doi:10.1007/s10894-016-00803.

[6] Velasquez CE, de Barros GP, Pereira C, Veloso MAF, Costa AL. Axial Neutron Flux Evaluation in a Tokamak System: A Possible Transmutation Blanket Position for a FusionFission Transmutation System. Brazilian J Phys 2012;42:237-47. doi:10.1007/s13538-0120081-2.

[7] Velasquez CE, Pereira C, Veloso MAF, Costa AL. Modelling effects on axial neutron flux in a Tokamak device. Prog Nucl Energy 2014;78:388-95. doi:10.1016/j.pnucene.2014.03.005.

[8] Hirai T, Escourbiac F, Barabash V, Durocher A, Fedosov A, Ferrand L, et al. Status of technology R\&D for the ITER tungsten divertor monoblock. J Nucl Mater 2015;463:1248-51. doi:10.1016/j.jnucmat.2014.12.027.

[9] Pitts RA, Bardin S, Bazylev B, van den Berg MA, Bunting P, Carpentier-Chouchana S, et al. Physics conclusions in support of ITER W divertor monoblock shaping. Nucl Mater Energy 2017;12:60-74. doi:10.1016/j.nme.2017.03.005.

[10] Hirai T, Panayotis S, Barabash V, Amzallag C, Escourbiac F, Durocher A, et al. Use of tungsten material for the ITER divertor. Nucl Mater Energy 2016;0:1-7. doi:10.1016/j.nme.2016.07.003.

[11] Rieth M, Dudarev SL, Gonzalez De Vicente SM, Aktaa J, Ahlgren T, Antusch S, et al. Recent progress in research on tungsten materials for nuclear fusion applications in Europe. J Nucl Mater 2013;432:482-500. doi:10.1016/j.jnucmat.2012.08.018.

[12] Terentyev D, De Temmerman G, Minov B, Zayachuk Y, Lambrinou K, Morgan TW, et al. Synergy of plastic deformation and gas retention in tungsten. Nucl Fusion 2015;55:1-5. doi:10.1088/0029-5515/55/1/013007.

[13] Tanure L, Bakaeva A, Dubinko A, Terentyev D, Verbeken K. Effect of annealing on microstructure, texture and hardness of ITER-specification tungsten analyzed by EBSD, vickers micro-hardness and nano-indentation techniques. J Nucl Mater 2019;524:191-9. doi:10.1016/j.jnucmat.2019.07.005.

[14] Neu R, Dux R, Kallenbach A, Pütterich T, Balden M, Fuchs J., et al. Tungsten: an option for divertor and main chamber plasma facing components in future fusion devices. Nucl Fusion 2005;45:209-18. doi:10.1088/0029-5515/45/3/007.

[15] Merola M, Escourbiac F, Raffray R, Chappuis P, Hirai T, Martin A. Overview and status of ITER internal components. Fusion Eng Des 2014;89:890-5. doi:10.1016/j.fusengdes.2014.01.055.

[16] Tanure L, Bakaeva A, Lapeire L, Terentyev D, Vilémová M, Matějíček J, et al. Nano-hardness, EBSD analysis and mechanical behavior of ultra-fine grain tungsten for fusion applications as plasma facing material. Surf Coatings Technol 2018;355:252-8. doi:10.1016/j.surfcoat.2018.01.075. 
[17] Suslova A, El-Atwani O, Sagapuram D, Harilal SS, Hassanein A. Recrystallization and grain growth induced by ELMs-like transient heat loads in deformed tungsten samples. Sci Rep 2015;4:6845. doi:10.1038/srep06845.

[18] Pfeifenberger MJ, Nikolić V, Žák S, Hohenwarter A, Pippan R. Evaluation of the intergranular crack growth resistance of ultrafine grained tungsten materials. Acta Mater 2019;176:330-40. doi:10.1016/j.actamat.2019.06.051.

550

[19] Abbaschian R, Abbaschian L, Reed-Hill RE. Physical Metallurgy Principles. 4th ed. Stamford: CENGAGE Learning; 2009.

[20] Riesch J, Aumann M, Coenen JW, Gietl H, Holzner G, Höschen T, et al. Chemically deposited tungsten fibre-reinforced tungsten - The way to a mock-up for divertor applications. Nucl Mater Energy 2016;9:75-83. doi:10.1016/j.nme.2016.03.005.

[21] Riesch J, Han Y, Almanstötter J, Coenen JW, Höschen T, Jasper B, et al. Development of tungsten fibre-reinforced tungsten composites towards their use in DEMO - potassium doped tungsten wire. Phys Scr 2016;T167:14006.

[22] Riesch J, Buffiere JY, Höschen T, Scheel M, Linsmeier C, You JH. Crack bridging in asfabricated and embrittled tungsten single fibre-reinforced tungsten composites shown by a novel in-situ high energy synchrotron tomography bending test. Nucl Mater Energy 2018;15:112. doi:10.1016/j.nme.2018.03.007.

[23] Horacsek O, Briant CL, Horacsek K. Effect of Heating Rate on the Recrystallization Behaviour of Doped Tungsten. High Temp Mater Process 1997;16:15-27. doi:10.1515/HTMP.1997.16.1.15.

[24] Briant CL, Horacsek O, Horacsek K. The effect of wire history on the coarsened substructure and secondary recrystallization of doped tungsten. Metall Trans A 1993;24:843-51. doi:10.1007/BF02656505.

[25] Schade P. Potassium bubble growth in doped tungsten. Int J Refract Met Hard Mater 1998;16:77-87. doi:10.1016/S0263-4368(98)00015-8.

[26] Terentyev D, Tanure L, Bakaeva A, Dubinko A, Nikolić V, Riesch J, et al. Micromechanical and microstructural properties of tungsten fibers in the as- produced and annealed state: Assessment of the potassium doping effect. Int J Refract Metals Hard Mater 2019;81:253-71. doi:10.1016/j.ijrmhm.2019.03.012.

[27] Terentyev D, Renterghem W Van, Tanure L, Dubinko A, Riesch J, Lebediev S. Correlation of microstructural and mechanical properties of K-doped tungsten fibers used as reinforcement of tungsten matrix for high temperature applications. Int J Refract Metals Hard Mater 2019;79:204-16. doi:10.1016/j.ijrmhm.2018.12.007.

[28] Nikolic V, Riesch J, Pippan R. The effect of heat treatments on pure and potassium doped drawn tungsten wires : Part I - Microstructural characterization. Mater Sci Eng A 2018;737:422-33. doi:10.1016/j.msea.2018.09.027.

[29] Terentyev D, Riesch J, Dubinko A, Khvan T, Zhurkin EE. Fracture surfaces of tungsten wires used in fiber-reinforced plasma facing components : Effect of potassium doping and high temperature annealing. Fusion Eng Des 2019:1-4. doi:10.1016/j.fusengdes.2019.01.137.

[30] Terentyev D, Riesch J, Lebediev S, Khvan T, Zinovev A, Rasinski M, et al. Plastic deformation of recrystallized tungsten-potassium wires : Constitutive deformation law in the temperature range $22-600^{\circ} \mathrm{C} 2018 ; 73: 38-45$. doi:10.1016/j.jirmhm.2018.01.012.

[31] Nikolic V, Riesch J, Pfeifenberger MJ, Pippan R. The effect of heat treatments on pure and potassium doped drawn tungsten wires : Part II - Fracture properties. Mater Sci Eng A 2018;737:434-47. doi:10.1016/j.msea.2018.09.029. 
[32] Gietl H, Riesch J, Coenen JW, Höschen T, Linsmeier C, Neu R. Tensile deformation behavior of tungsten fibre-reinforced tungsten composite specimens in as-fabricated state. Fusion Eng Des 2017;124:396-400. doi:10.1016/j.fusengdes.2017.02.054.

[33] Zhao P, Riesch J, Höschen T, Almanstötter J, Balden M, Coenen JW, et al. Microstructure, mechanical behaviour and fracture of pure tungsten wire after different heat treatments. Int $\mathbf{J}$ Refract Met Hard Mater 2017;68:29-40. doi:10.1016/j.ijrmhm.2017.06.001.

[34] Schade P. 100 Years of Doped Tungsten Wire. Int J Refract Met Hard Mater 2010;28:648-60. doi:10.1016/j.jirmhm.2010.05.003.

[35] Terentyev D, Dubinko A, Riesch J, Lebediev S, Volkov I, Zhurkin EE. Performance of tungsten fibers for Wf/W composites under cyclic tensile load. Int J Refract Met Hard Mater 2020;86:105094. doi:10.1016/j.jirmhm.2019.105094.

[36] Chen Y, Li J, Tang B, Kou H, Zhang F, Chang H, et al. Grain boundary character distribution and texture evolution in cold-drawn Ti-45Nb wires. Mater Lett 2013;98:254-7. doi:10.1016/j.matlet.2013.02.043.

[37] Brandon DG. The Structure of High-Angle Grain Boundaries. Acta Metall 1966;14:1479-84. doi:10.1002/pssb.19690310123.

[38] Watanabe T, Fujii H, Oikawa H, Arai KI. Grain boundaries in rapidly solidified and annealed Fe-6.5 mass\% Si polycrystalline ribbons with high ductility. Acta Metall 1989;37:941-52. doi:10.1016/0001-6160(89)90021-7.

[39] Gil Sevillano J, González D, Martínez-Esnaola JM, Novelis, Partnership EM. Heterogeneous deformation and internal stresses developed in BCC wires by axisymmetric elongation. Int Symp Fundam Deform Annealing 2007;550:75-84. doi:10.4028/0-87849-434-0.75.

[40] Engler O, Randle V. Introduction to texture analysis. second. Taylor \& Francis; 2010. doi:10.1142/9781848161160_0001.

[41] Humphreys FJ, Hatherly M. Recrystallization and Related Annealing Phenomena: Second Edition. 2004. doi:10.1016/B978-0-08-044164-1.X5000-2.

[42] Vervynckt S, Verbeken K, Lopez B, Jonas JJ. Modern HSLA steels and role of nonrecrystallisation temperature. Int Mater Rev 2012;57:187-207. doi:10.1179/1743280411Y.0000000013.

[43] Hughes DA, Hansen N. High angle boundaries formed by grain subdivision mechanisms. Acta Mater 1997;45:3871-86. doi:10.1016/S1359-6454(97)00027-X.

[44] Lied P, Bonnekoh C, Pantleon W, Stricker M, Hoffmann A, Reiser J. Comparison of K-doped and pure cold-rolled tungsten sheets: As-rolled condition and recrystallization behaviour after isochronal annealing at different temperatures. Int J Refract Met Hard Mater 2019;85:105047. doi:10.1016/j.ijrmhm.2019.105047.

[45] Engler O, Huh MY. Evolution of the cube texture in high purity aluminum capacitor foils by continuous recrystallization and subsequent grain growth. Mater Sci Eng A 1999;271:371-81. doi:10.1016/s0921-5093(99)00254-3.

[46] Tanure L, Bakaeva A, Lapeire L, Terentyev D, Vilémová M, Matějíček J, et al. Nano-hardness, EBSD analysis and mechanical behavior of ultra-fine grain tungsten for fusion applications as plasma facing material. Surf Coatings Technol 2018;355. doi:10.1016/j.surfcoat.2018.01.075.

[47] Randle V. Twinning-related grain boundary engineering. Acta Mater 2004;52:4067-81. doi:10.1016/j.actamat.2004.05.031.

[48] Qian J, Wu CY, Fan JL, Gong HR. Effect of alloying elements on stacking fault energy and ductility of tungsten. J Alloys Compd 2018;737:372-6. doi:10.1016/j.jallcom.2017.12.042. 
[49] Lin PK-Y. Evolution of Grain Boundary Character Distributions in FCC and BCC Materials. Thesis 1997:139.

[50] Gertsman VY. Geometrical theory of triple junctions of CSL boundaries. Acta Crystallogr Sect A Found Crystallogr 2001;57:369-77. doi:10.1107/S0108767301000654.

[51] Frary M, Schuh CA. Combination rule for deviant CSL grain boundaries at triple junctions. Acta Mater 2003;51:3731-43. doi:10.1016/S1359-6454(03)00188-5.

[52] King WE, Stolken JS, Kumar M, Schwartz AJ. Electron Backscatter Diffraction in Materials

[53] Tanure L, Terentyev D, Riesch J, Verbeken K. Evolution of microstructure, texture and grain boundary character distribution of potassium doped tungsten fibers annealed at variable temperatures. J Phys Conf Ser 2019;1270:12038. doi:10.1088/1742-6596/1270/1/012038. 